Article

\title{
Reemergence of Measles in the Americas: The Genotype B3 2011-2012 Outbreak in Ecuador
}

\author{
Nicole K. Le ${ }^{1, *}$, Rahul Mhaskar ${ }^{2}$, Ismael Hoare ${ }^{3}$, Mauricio Espinel ${ }^{4}$, \\ María Fernanda Rivadeneira ${ }^{5}$, Sharad Malavade ${ }^{6}$ and Ricardo Izurieta ${ }^{3}$ \\ 1 Morsani College of Medicine, University of South Florida, Tampa, FL 33612, USA \\ 2 Center for Evidence Based Medicine and Health Outcomes Research, University of South Florida, \\ Tampa, FL 33612, USA; rmhaskar@health.usf.edu \\ 3 Department. of Global Health, College of Public Health, University of South Florida, Tampa, FL 33612, USA; \\ ihoare@health.usf.edu (I.H.); rizuriet@health.usf.edu (R.I.) \\ 4 School of Medicine, Universidad Laica Eloy Alfaro de Manabi, Manta 13052732, Ecuador; \\ espinel.mauricio@yahoo.com \\ 5 School of Medicine, Pontifical Catholic University of Ecuador, Quito 170109, Ecuador; \\ maferivadeneira@yahoo.com \\ 6 Department of Internal Medicine, Brandon Regional Hospital, Brandon, FL 33511, USA; \\ smalavad@health.usf.edu \\ * Correspondence: nicole.le93@gmail.com; Tel.: +1-813-974-8913
}

Academic Editor: Rachel L. Roper

Received: 20 March 2017; Accepted: 27 May 2017; Published: 2 June 2017

\begin{abstract}
This study characterizes a measles outbreak which occurred in Ecuador in 2011-2012, analyzing data from 3700 suspected cases of measles reported to Ecuador's Ministry of Public Health. The study population had a large age range and included 333 confirmed cases of measles. The greatest number of cases were found in the $<1$ year $(32.43 \%, n=108)$ and $1-4$ year $(30.03 \%, n=100)$ age-groups. Compared to Mestizos, indigenous people had the highest number of cases $(68.2 \%, n=227)$, as well as a higher risk of infection (OR 7.278 (CI 5.251-10.087)). The greatest protection from measles was observed in individuals who received two doses of the measles vaccine. Residents of Pastaza (OR 6.645 CI (3.183-13.873)) and Tungurahua (OR 8.346 CI (5.570-12.507)) had a higher risk of infection than the other provinces. Of the 17 laboratory confirmed cases, all were identified as genotype B3. Age-group, ethnicity, measles vaccinations, and residence in Tungurahua and Pastaza were correlated with rates of measles infection in the outbreak. Tungurahua and Pastaza, where the outbreak originated, have large indigenous populations. Indigenous children $<1$ year of age showed the highest incidence. It is likely that indigenous women do not have immunity to the virus, and so are unable to confer measles resistance to their newborns.
\end{abstract}

Keywords: measles; vaccinations; Ecuador; indigenous

\section{Introduction}

Of all the regions in the world, the Americas was the first to eliminate measles [1]. This interruption of the endemic transmission of measles was no easy task, considering that it is a highly contagious viral disease [2]. Following Cuba's successful vaccination programs, a plan was enacted at the XXIV Pan American Sanitary Conference in 1994 with the goal of eliminating the measles virus $(\mathrm{MeV})$ in the Americas by the year $2000[3,4]$.

To achieve this, countries enacted the Pan American Health Organization (PAHO) three step strategy [3]. First, they started with a national "catch-up" vaccination campaign in order to rapidly increase immunity and interrupt the transmission of $\mathrm{MeV}$. They did so by vaccinating all children 
aged 1-14 years regardless of disease and vaccination history [3]. The second step was to "keep-up" vaccinations. Routine vaccination services were strengthened to provide at least $95 \%$ coverage of all one-year-olds [3]. Since encounters with the virus were less likely after the "catch-up" campaign, the routine vaccination age was increased from nine months to one year of age, further increasing the efficacy of the vaccine [3]. In order to ensure high vaccination rates, quadrennial "follow-up" vaccination campaigns targeted children aged 1-5 years regardless of previous infection or vaccination history [3].

An additional strategy, "mop-up" vaccination campaigns, targeted groups of unvaccinated children, particularly in urban or hard-to-reach rural areas [3]. These campaigns also targeted regions with outbreaks of measles cases, weak surveillance of measles, low access to health services, and regions with high poverty and migration populations [5]. High risk groups having low coverage with the standard two-dose vaccination schedule included: impoverished regions with high population density and poor sanitation; communities philosophically opposed to immunization (e.g., indigenous populations which only trusted their traditional healers or shamans, Amish communities, or the anti-vaccine movement); young migratory adults who travel from low density rural areas to highly dense urban areas; persons working or living in close proximity to tourist destinations and in the tourist industry; geographically remote populations; college students; medical professionals; and international travelers [2,6-10]. It was found that house-to-house vaccination, along with house-to-house surveillance of measles, were the most efficient approaches for reaching high vaccination rates in at-risk populations [11].

To increase coverage, immunization programs provided vaccinations to entire households [7]. In the 2000s, efforts to promote the elimination of $\mathrm{MeV}$ were strengthened by the joint implementation of measles and rubella "speed-up" campaigns that also targeted women of childbearing age (12-29 years) [12]. The objectives were to reduce the risk for congenital rubella syndrome and ensure mothers had immunity that could be conferred to their infant during the first 6-12 months of life [13]. Through this strategy, the aim was to transfer maternal antibodies to protect the infant until the vaccination scheduled on the first birthday.

Considering the current progress toward the elimination of $\mathrm{MeV}$, the most pressing concern is to sustain those achievements which requires governments to maintain and raise coverage rates through national immunization programs [1]. This current progress may be increased through effective surveillance and further mass immunization programs [1]. To maintain reliable herd immunity from measles, immunization coverage rates need to be at least $90 \%$ [12]. Obstacles to the elimination of $\mathrm{MeV}$ include the accumulation of susceptible children over time and the continual circulation of the $\mathrm{MeV}$ in other regions of the world, particularly in Southeast Asia, Africa, and Europe [7,12]. Notably, all genotypes, from the outbreaks since 2003, have been identified as nonindigenous to the Americas [14,15].

The 2011-2012 outbreak in Ecuador was quite alarming, as the country had been MeV free since 1997 [16]. This MeV free period was made possible by large vaccination efforts and was supported by the implementation of the National Vaccine Law which was enacted in 1999. This particular law mandated funding for nationwide vaccination campaigns, including both the administration of existing vaccines and newly developed vaccines [8]. Through this law, the Organic Health Law, and Ecuador's Constitution, vaccinations were guaranteed as a public good, ensuring legal support for the Expanded Program on Immunization [12].

The study describes the key characteristics of the measles outbreak which occurred in Ecuador during 2011-2012. It outlines the risks to the Mestizo and Indigenous populations in Ecuador.

\section{Materials and Methods}

The information for this research was obtained from the database of the National Surveillance System Eruptive Non Vesicular Disease (EFENV), the Ministerio de Salud Publica (MSP) of Ecuador (Ministry of Public Health). This retrospective cross sectional outbreak study was approved by the 
Institutional review board (no. Pro00029260) at the University of South Florida. The data from the 2011-2012 measles epidemic in Ecuador was collected by the MSP of Ecuador under the Expanded Immunization Program. This included clinical characteristics of cases and suspected cases of measles. A case of measles was defined as a laboratory confirmed case of measles, or a primary contact of a laboratory confirmed case of measles exhibiting signs and symptoms of measles. Seventeen suspected cases of measles were tested using laboratory tests (blood, nasopharyngeal swab, and urine tests) to confirm infection with $\mathrm{MeV}$, and genotyping. All the samples were processed in the MSP central laboratories. Information was collected on the vaccination status of the individual, number of doses of $\mathrm{MeV}$ vaccine received, age group, gender, province of residence, and ethnicity (see the Supplementary Materials file).

The study population included 3700 individuals reported as suspected cases of measles to the measles surveillance system. The inclusion criteria was a classification as "suspicious" by the EFENV for measles, presenting with exanthema and fever, between the years of 2011 and 2012. The exclusion criteria was the absence of the classical signs of measles (i.e., fever and rash), as reported by the surveillance system EFENV. The sampling frame consisted of patients with suspected measles, which were detected and reported by health institutions, public or private, and entered into the EFENV Surveillance System from 2011 until 2012. The statistical software SPSS v22 and SAS v9.4 were used, accessed from the University of South Florida. Descriptive statistics using frequency counts and Chi-square analyses were done to assess the study sample characteristics. Logistic regression analyses using stepwise selection was performed to identify factors associated with measles infection.

\section{Results}

Of the 3700 patients, 333 patients met the case definition by laboratory confirmation or epidemiologic linkage. Of the 333 cases, $49.5 \%$ were males and $50.5 \%$ were females. The ethnicities of the measles cases were $68.2 \%$ Indigenous (Amerindian descendants) and 31.8\% were Mestizos (mixed race of Spanish and Amerindian descendants). When comparing the percentage of the measles cases within the entire population of Ecuador, patients $<1$ year comprised of $0.0415 \%$, patients 1 year to 4 years involved $0.0083 \%$, patients 5 years to 9 years included $0.0024 \%$, patients 10 years to 14 years consisted of $0.0030 \%$, patients 15 years to 19 years made up $0.0010 \%$, patients 20 years to 39 years were $0.0005 \%$, and patients 40 years and older were $0.0001 \%$ of the population (Figure 1 ).

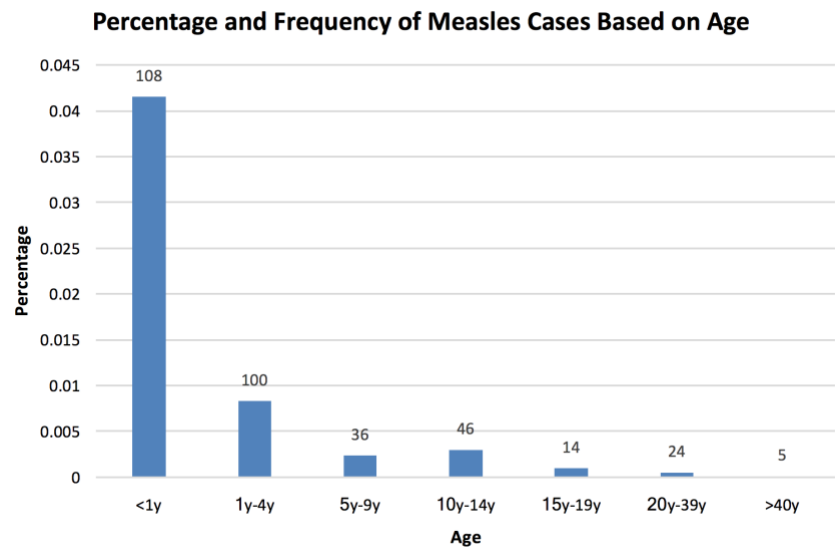

Figure 1. Percentage and frequency of measles cases based on age. Out of the 333 measles cases, the percentages and number of people within each age group are presented. The percentages have been adjusted for each age group over the entire Ecuadorian population. The frequency of each group is labelled above each bar.

Of the people with measles cases, $74.3 \%$ had zero doses of the MeV vaccine, $24.8 \%$ only had 1 dose, $0.6 \%$ had 2 doses, and $0.3 \%$ had $3-7$ doses. Of the $74.3 \%$ who did not receive any vaccine dose, 
$60.1 \%$ did not provide a reason while $14.2 \%$ were not eligible for the vaccine as they were younger than 12 months, pregnant, or had a concomitant disease. (Figure 2). Figure 3 shows the percentage of measles cases in each province. Of the nine provinces that had cases of measles, $48.6 \%$ were residents of Tungurahua, 15.3\% from Pichincha, 11.1\% from Guayas, and 9.0\% from Pastaza. Morona Santiago, Cotopaxi, Santo Domingo, Chimborazo, and Manabi had the remaining cases of measles.

\section{Percentage of Measles Cases by Number of MeV Vaccine Doses}

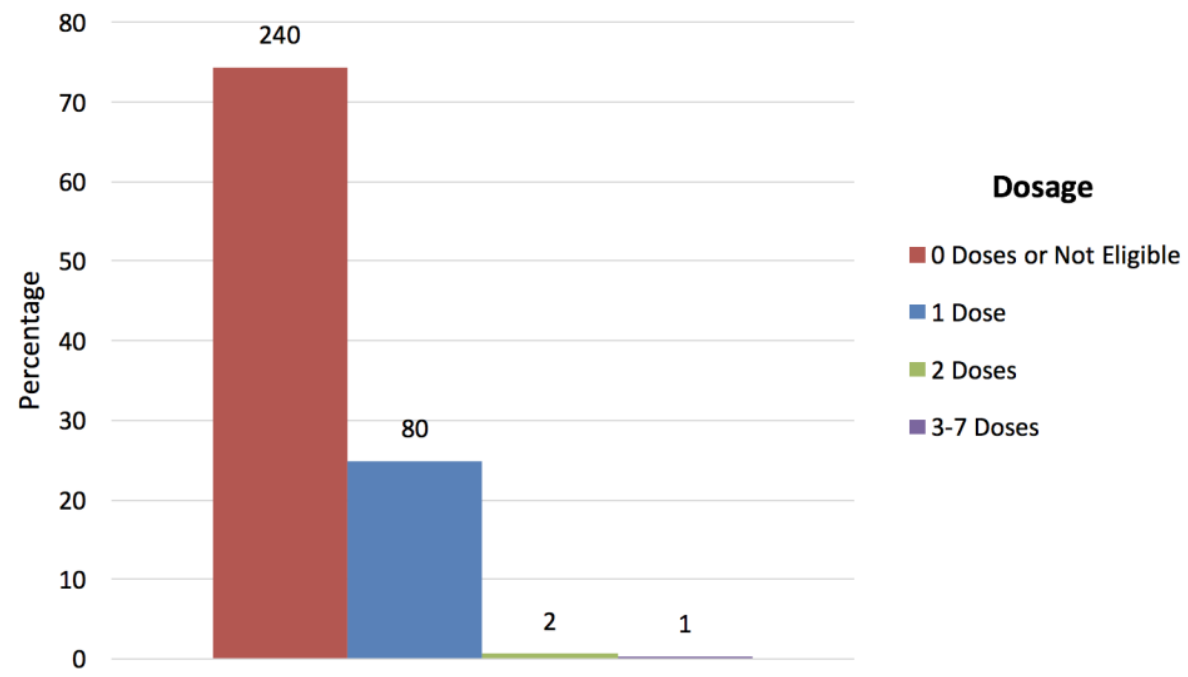

Figure 2. Percentage of measles cases by number of $\mathrm{MeV}$ vaccine doses. Out of the 333 measles cases, the percentages and number of people are presented for each number of $\mathrm{MeV}$ vaccine dose. The frequency of each group is labelled above each bar. People not eligible for the vaccine were grouped with "0 Doses".

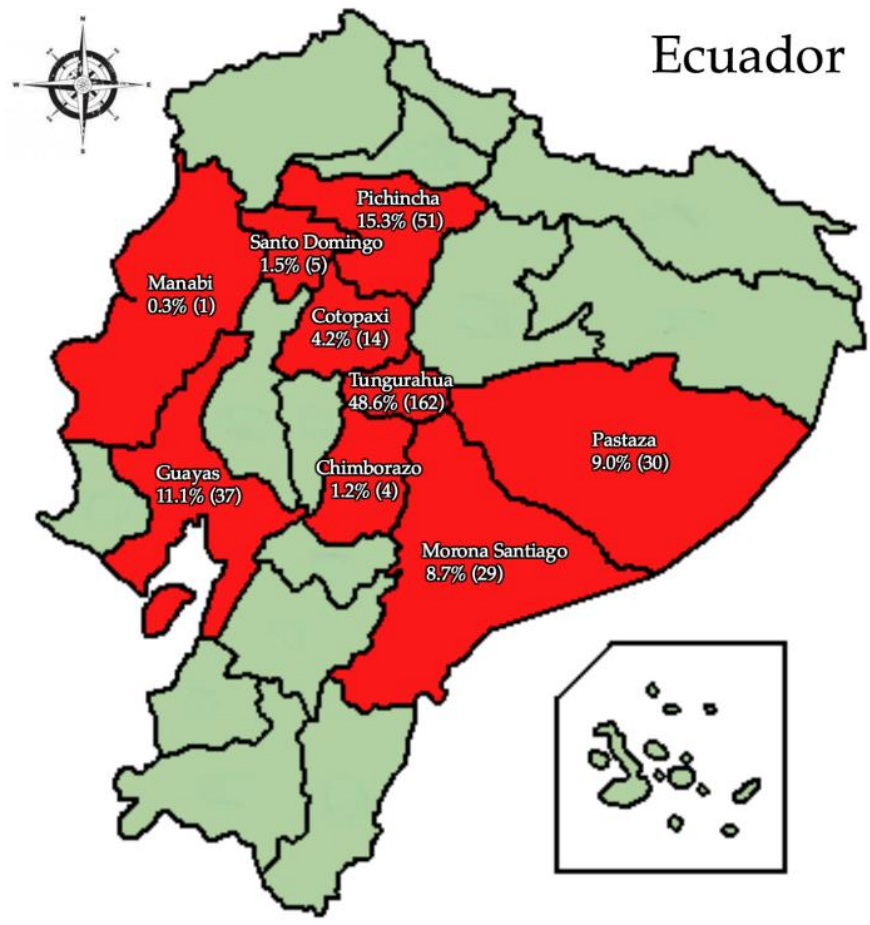

Figure 3. Percentage of measles cases by province in Ecuador. Out of the 333 measles cases, the percentages of cases each province had is shown. The frequency of cases in each province is also included in the parentheses. 
Of the people with measles, $49.7 \%$ of the Mestizos and $57.9 \%$ Indigenous persons had never received a $\mathrm{MeV}$ vaccine (Table 1). The genotype B3 was found for all 17 laboratory-confirmed cases. Figure 4 demonstrates that $30.8 \%$ of the indigenous and $35.9 \%$ of the Mestizos with measles were younger than one year. The next highest incidence of measles was within the 1-4 years age group with $30.4 \%$ being indigenous and $29.2 \%$ were Mestizos (Figure 4 ).

Table 1. Distribution of study population based on ethnicity and vaccination status. Out of the entire study population, the percentages of Indigenous and Mestizo persons with and without vaccinations are shown. The frequency of each group is labelled above each bar.

\begin{tabular}{ccccc}
\hline \multirow{2}{*}{ Vaccine Status } & \multicolumn{2}{c}{ Indigenous } & \multicolumn{2}{c}{ Mestizo } \\
\cline { 2 - 5 } & Percentage & Frequency & Percentage & Frequency \\
\hline Did not receive measles vaccine & $57.85 \%$ & 280 & $49.67 \%$ & 1375 \\
Received measles vaccine & $42.15 \%$ & 204 & $50.34 \%$ & 1393 \\
\hline
\end{tabular}

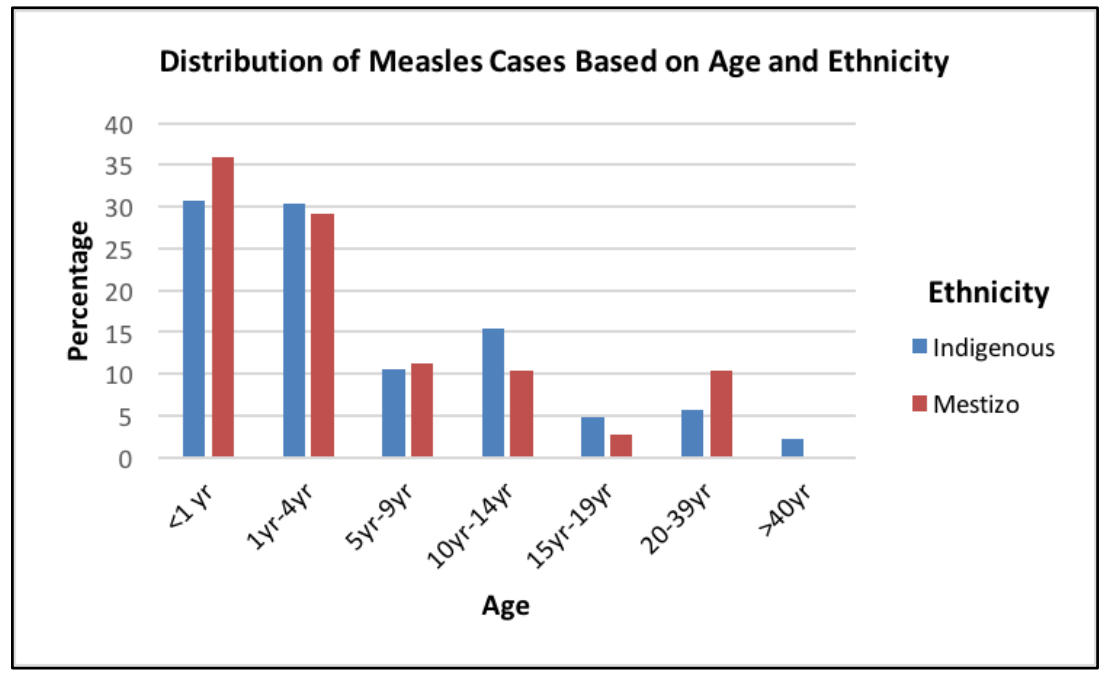

Figure 4. Distribution of measles cases based on age and ethnicity. Out of the 333 measles cases, the percentage of both Indigenous and Mestizo persons are shown within each age group.

When determining the risk of getting measles, people with no vaccine had an odds ratio and $95 \%$ confidence interval of $34.85(8.001,151.62)$ when compared to those with two doses of the vaccine. The odds ratio of indigenous compared to Mestizos was 7.28 (5.25, 10.09). Out of the provinces, when compared to Azuay, the provinces with the highest odds ratio were Pastaza with an odds ratio of $6.65(3.18,13.87)$ and Tungurahua with an odds ratio of $8.35(5.57,12.51)$.

\section{Discussion}

This study found that the greatest risk factor for contracting measles was lack of vaccination. In addition, the indigenous persons in Ecuador had a greater risk of contracting measles. Factors which may have contributed to this increased risk include: poor access to preventive services, living in remote geographic locations which can impede outreach program efforts, the difficulty of maintaining vaccine refrigeration chains, poverty, cultural differences, and malnutrition [17]. The provinces at highest risk, including Pastaza and Tungurahua, have large indigenous populations. Mestizos have, on average, a higher socio-economic status compared to the indigenous populations in Ecuador [18]. These inequities, especially in the health system, greatly impact the indigenous populations and may exacerbate a measles outbreak [17]. 
Children under the age of five were at the greatest risk for measles. Children under one year with measles lacked maternal immunity to the virus because their mothers were never vaccinated nor exposed to the $\mathrm{MeV}$. The vaccination strategy for Ecuador for the year 2010 mandated two doses total at age one year and six years [19]. With a lack of maternal immunity, children under one year were vulnerable until their first dose of the vaccine $[13,19]$. Due to the increased rates of measles infection within the 1-4 years group, it is likely that these children also did not receive the $\mathrm{MeV}$ vaccine.

Measles did not affect one gender more than the other. We found that the number of doses received was negatively correlated with the risk of infection. There was a slight increase in measles cases for people who received 3-7 doses of the vaccine. A possible explanation for this was poor record keeping, as the standard dosing schedule is two doses total.

When the MeV were genotyped, the B3 genotype was found, which is endemic to Africa and parts of Europe. Individuals from Europe, particularly Spain, and Africa, may have imported the virus into Ecuador. Large populations of Ecuadoreans live in Spain, as a result of the mass emigration from Ecuador that occurred during the economic crisis of 1990 [20]. Ecuadoreans returning from Spain may have been infected with the virus during an outbreak and brought it to Ecuador. The government may have classified many of these Ecuadoreans as tourists because they applied for tourist visas for their visits, rather than filing as returning Ecuadorian citizens due to the former method's relative simplicity of entry. A large portion of the people who migrated were the indigenous population seeking employment in domestic service, construction, and agriculture in Spain [21]. It is likely that a good number of them were not vaccinated prior to their emigration, and the low vaccination coverage rates in Europe left them vulnerable to $\mathrm{MeV}$ [22].

Furthermore, African migrants started migrating to Ecuador when the Ecuadorean government lifted all travel visa requirements in 2008 [23]. The influx of Africans, who may have been carrying the $\mathrm{MeV}$, may have contributed to the outbreak. Most of the outbreaks in the Americas have been linked to the large number of outbreaks affecting Africa and Europe [24]. The long period of absence of measles cases ended in the 26th epidemiological week of 2011 [25]. The MeV genotype B3's presence, seen circulating in Spain and Kenya, was confirmed in Ecuador [26,27].

The South African FIFA World Cup in June-July 2010 was a possible explanation for the presence of $\mathrm{MeV}$ genotype B3 virus in Ecuador, since it is a commonly held theory in epidemiology that transmission of contagious diseases increases during major international gatherings, such as the World Cup and other similar events [12,28]. However, the idea that the World Cup led to the outbreak is unlikely due to the gap in time between the World Cup and the measles outbreak. The MeV incubation period is only a mere 10-12 days, not an entire year [2].

To prevent future outbreaks, increased vaccination coverage, especially among the indigenous population and younger children, should be increased. Vaccination of females in the reproductive age group would ensure that maternal immunity is passed on to her child so that children younger than one year would be better protected, and herd immunity is further strengthened. In addition, epidemiological surveillance systems need to be strengthened to better respond to future outbreaks.

Finally, we advise against a reduction of surveillance and vaccination activities that are necessary for the elimination of $\mathrm{MeV}$. Often, when a disease is eliminated from a country or region, the governments stop viewing the disease as a real and urgent threat [29]. As a result, disease monitoring and vaccination programs are abandoned, laxly enforced, or underfunded. This leaves countries, especially developing nations, vulnerable to the reintroduction of $\mathrm{MeV}$. We advise that, even after elimination in a particular region, governments should remain vigilant in enforcing their vaccination policies, as the virus is still circulating in other parts of the world.

When surveillance and vaccination efforts are maintained for long periods of time, we can eliminate the virus from progressively larger areas. After numerous spikes in measles outbreaks across the Americas, countries on both continents have collaborated to interrupt endemic transmission of $\mathrm{MeV}$. They increased vaccination efforts and surveillance, and in September 2016, the Pan American Health Organization declared that the region of the Americas had eliminated MeV [30]. 
Our study was limited by missing data points for several of our variables. To improve, a more complete data set would be preferable for more robust conclusions. Furthermore, while there were 333 confirmed cases of measles, only 17 of these cases were lab confirmed. Even though the remaining 316 cases were primary contacts of the lab confirmed cases with the classic signs and symptoms of measles, it is possible that they either were not cases of measles, or not the B3 genotype.

\section{Conclusions}

The reemergence of $\mathrm{MeV}$ was unexpected in the Americas, especially in Ecuador, after previously achieving elimination. The B3 genotype was found to be predominant during the 2011-2012 outbreak, and the greatest risk factor for its reemergence was the lack of vaccination. The people most likely to contract $\mathrm{MeV}$ during the outbreak were children five years and younger, while the indigenous populations were found to be more at risk than Mestizos. Despite much progress, more work is needed before the elimination of $\mathrm{MeV}$ becomes a reality. The Americas have set a good example to follow, and with the necessary amount of international cooperation and effort, the global elimination of $\mathrm{MeV}$ may soon be achieved.

Supplementary Materials: The following are available online at www.mdpi.com/2076-393X/5/2/15/s1.

Acknowledgments: We would like to thank USF College of Public Health and the Ministry of Public Health, Ecuador.

Author Contributions: Ricardo Izurieta and Ismael Hoare conceived and designed the experiments; Mauricio Espinel and María Fernanda Rivadeneira performed the experiments; Nicole K. Le, Rahul Mhaskar, and Sharad Malavade analyzed the data; Nicole K. Le wrote the paper.

Conflicts of Interest: The authors declare no conflict of interest.

\section{References}

1. Pan American Health Organization. Health in the Americas; Pan American Health Organization: Washington, DC, USA, 2007; Volume 1.

2. National Immunization Program (Centers for Disease Control and Prevention). Epidemiology and Prevention of Vaccine-Preventable Diseases Course Textbook. Available online: https://www.cdc.gov/ vaccines/pubs/pinkbook/downloads/meas.pdf (accessed on 31 May 2016).

3. De Quadros, C.A.; Olive, J.M.; Hersh, B.S.; Strassburg, M.A.; Henderson, D.A.; Brandling-Bennett, D.; Alleyne, G.A. Measles elimination in the Americas. Evolving strategies. JAMA 1996, 275, 224-229. [CrossRef] [PubMed]

4. Pan American Health Organization. XXIV Meeting of the Pan American Sanitary Conference, Washington, DC., USA, 27 September-1 October, 1993; Pan American Health Organization: Washington, DC, USA, 1993.

5. Pan American Health Organization. Measles Eradication Field Guide; ProQuest: Washington, DC, USA, 1999; p. 28.

6. Pan American Sanitary Bureau. Health in the Americas. In PAHO Scientific and Technical Publications, 1993-1996 ed.; Pan American Health Organization, Pan American Sanitary Bureau, Regional Office of the World Health Organization: Washington, DC, USA, 1998.

7. Pan American Health Organization. Special program of vaccines and immunization. In Proccedings of the Conclusions and Recommendations: XII Technical Advisory Group Meeting on Vaccine-Preventable Diseases, Guatemala, Guatemala, 8-12 September 1997.

8. Pan American Health Organization. Health in the Americas, 2007 ed.; Pan American Health Organization: Washington, DC, USA, 2007; Volume 2.

9. Centers for Disease Control and Prevention. Measles Cases and Outbreaks. Available online: http://www. cdc.gov/measles/cases-outbreaks.html (accessed on 31 May 2016).

10. Pan American Health Organization. Division of vaccines and immunization. In Proccedings of the Conclusions and Recommendations: XIII Technical Advisory Group Meeting on Vaccine-Preventable Diseases, Gatineau, QC, Canada, 12-16 April 1999; p. 5. 
11. Pan American Health Organization. Measles outbreak in an isolated community in Bolivia. EPI Nezwslett. 2000, 22, 1-3.

12. Pan American Health Organization. Health in the Americas: Regional Outlook and Country Profiles, 2012 ed.; Pan American Health Organization: Washington, DC, USA, 2012.

13. Sato, H.; Albrecht, P.; Reynolds, D.W.; Stagno, S.; Ennis, F.A. Transfer of measles, mumps, and rubella antibodies from mother to infant: Its effect on measles, mumps, and rubella immunization. Am. J. Dis. Child. 1979, 133, 1240-1243. [CrossRef] [PubMed]

14. Rota, P.A.; Rota, J.S.; Redd, S.B.; Papania, M.J.; Bellini, W.J. Genetic analysis of measles viruses isolated in the United States between 1989 and 2001: Absence of an endemic genotype since 1994. J. Infect. Dis. 2004, 189, S160-S164. [CrossRef] [PubMed]

15. De Quadros, C.A.; Izurieta, H.; Venczel, L.; Carrasco, P. Measles eradication in the Americas: Progress to date. J. Infect. Dis. 2004, 189, S227-S235. [CrossRef] [PubMed]

16. Pan American Health Organization. Health in the Americas, 2002 ed.; Pan American Health Organization: Washington, DC, USA, 2002.

17. Puertas, B.; Schlesser, M. Assessing community health among indigenous populations in ecuador with a participatory approach: Implications for health reform. J. Community Health 2001, 26, 133-147. [CrossRef] [PubMed]

18. Sánchez, J. Inequality, Ethnicity and Social Disorder: The Ecuadorian Case; Third World Bank Conference on Inequality: Washington, DC, USA, 2006.

19. UNICEF and WHO. Immunization Summary - A Statistical Reference Containing Data through 2010, 2012 ed.; Unicef: New York, NY, USA, 2012.

20. Margheritis, A. “Todos somos migrantes" (we are all migrants): The paradoxes of the innovative state-led transnationalism in Ecuador. Int. Political Sociol. 2011, 5, 198-217. [CrossRef]

21. Jokisch, B.D. Ecuador: From Mass Emigration to Return Migration? Available online: http://www. migrationpolicy.org/article/ecuador-mass-emigration-return-migration (accessed on 1 June 2016).

22. Mankertz, A.; Mulders, M.N.; Shulga, S.; Kremer, J.R.; Brown, K.E.; Santibanez, S.; Muller, C.P.; Tikhonova, N.; Lipskaya, G.; Jankovic, D.; et al. Molecular genotyping and epidemiology of measles virus transmission in the World Health Organization European Region, 2007-2009. J. Infect. Dis. 2011, 204, S335-S342. [CrossRef] [PubMed]

23. Freier, L.F. A Gateway to the Americas: Ecuador's "Policy of Open Doors" as a Natural Experiment. Available online: http:/ / paperroom.ipsa.org/papers/view/18248 (accessed on 29 May 2016).

24. World Health Organization. Measles Outbreaks: REGIONS of the Americas, Europe and Africa. Available online: http://www.who.int/csr/don/2011_10_07/en/ (accessed on 29 May 2016).

25. Pan American Health Organization. Paving the way for immunization. In Proceedings of the XX Technical Advisory Group Meeting on Vaccine-Preventable Diseases; Washington, DC, USA, 17-19 October 2012.

26. Centers for Disease Control and Prevention. Increased Transmission and Outbreaks of Measles-European Region, 2011. Available online: https://www.cdc.gov/mmwr/preview/mmwrhtml/mm6047a1.htm (accessed on 31 May 2016).

27. Andrus, J.K.; Vicari, A.; Tambini, G.; Periago, M.R. The global inter-relatedness of disease control. Lancet Infect. Dis. 2007, 7, 176. [CrossRef]

28. Williams, C.J.; Schenkel, K.; Eckmanns, T.; Altmann, D.; Krause, G. FIFA World Cup 2006 in Germany: Enhanced surveillance improved timeliness and detection. Epidemiol. Infect. 2009, 137, 597-605. [CrossRef] [PubMed]

29. Hasan, H. Measles Initiative Partners Gear up to Tackle Challenges Ahead; WHO: Geneva, Switzerland, 2011.

30. 55th Directing Council of the 68th Session of the Regional Committee of WHO for the Americas. Available online: https://www.google.ch/url?sa=t\&rct=j\&q=\&esrc=s\&source=web\&cd=2\&ved=0ahUKEwjms68jpnUAhXpIMAKHZ_TBSYQFggqMAE\&url=http\%3A\%2F\%2Firis.paho.org\%2Fxmlui\%2Fbitstream\% 2Fhandle\%2F123456789\%2F33696\%2FCD55-DIV-12-e.pdf\%3Fsequence\%3D1\%26isAllowed \%3Dy\&usg= AFQjCNHyUw5xiTuofDaWn0ZhajaN3d9KFQ\&cad=rja (accessed on 31 May 2016).

(C) 2017 by the authors. Licensee MDPI, Basel, Switzerland. This article is an open access article distributed under the terms and conditions of the Creative Commons Attribution (CC BY) license (http:/ / creativecommons.org/licenses/by/4.0/). 